DOI:

\title{
INSECTICIDAL EFFECTS OF TWO MEDICINAL PLANTS Polygonum hydropiper L. AND Abrus precatorius L. LEAVES AGAINST THE RICE WEEVIL Sitophilus oryzae L. (COLEOPTERA: CURCULIONIDAE)
}

\author{
Bhattacharjee, S. C., M. M. Matin ${ }^{1}$ and M. Nasiruddin ${ }^{2}$ \\ BCSIR Laboratories Chittagong, Chemical Research Division, Baluchara, Chattagram, Bangladesh; \\ ${ }^{1}$ Department of Organic Chemistry, University of Chittagong, Chittagong, Bangladesh; ${ }^{2}$ Department of \\ Zoology, University of Chittagong, Chittagong 4331, Bangladesh
}

\begin{abstract}
During the study, the leaves of two medicinal plants, Polygonum hydropiper and Abrus precatorius were extracted with water, ethanol, methanol and petroleum ether solvents and tested against the rice weevil $S$. oryzae L. for insecticidal properties. Response varied with plant species. The mortality of adults increased with increasing dose concentrations from $1000 \mathrm{ppm}$ to $5000 \mathrm{ppm}$ each solution, with an exposure time of 72 hours. $\mathrm{LC}_{50}$ values calculated were found to be $15091.436 \mathrm{ppm}$ with water, $5051.534 \mathrm{ppm}$ with ethanol, 5111.063 ppm with methanol and $4305.348 \mathrm{ppm}$ with petroleum ether extracts of $P$. hydropiper and $9687.292 \mathrm{ppm}$ with water, $6263.849 \mathrm{ppm}$ with ethanol, $4682.683 \mathrm{ppm}$ with methanol and $3222.984 \mathrm{ppm}$ with petroleum ether extracts of Abrus precatorius leaves corresponding their concentrations of the leaf extract solutions at $1000 \mathrm{ppm}, 2000 \mathrm{ppm}, 3000 \mathrm{ppm}, 4000 \mathrm{ppm}$ and $5000 \mathrm{ppm}$ respectively. The results of the study showed that methanol and petroleum ether extrcts of $P$. hydropiper and ethanol, methanol and petroleum ether extracts of A. precatorius showed good toxicity. It appeared that the leaf extracts had some insecticidal activities against S. oryzae adult.
\end{abstract}

Key words: Polygonum hydropiper; Abrus precatorius; Leaf; Mortality; $\mathrm{LC}_{50}$; Relative potency.

\section{INTRODUCTION}

Stored grain losses of major cereal crops can be attributed primarily to attack by insect pests. There is a need to protect the stored grains against deterioration both qualitatively and quantitatively during storage due to insect attack. Agricultural stored and animal origin products are attacked by more than 600 species of beetles, 70 species of moths and about 355 species of mites, which cause quantitative and qualitative losses (Rajendra and Sriranjini 2008). This damage may cause loss to about 5 to $10 \%$ in temperate zone and 20 to $30 \%$ in tropical zone (Hague et al. 2000). These stored commodities are vulnerable to insect attack and the quality is deteriorated. Loss in weight of grains is a great economic problem. One of the major cosmopolitan pests of stored commodities in tropical countries is 'rice weevil', Sitophilus oryzae L. (Coleoptera: Curculionidae). One pair of S. oryzae can reproduce about one million of its species with in a period of three months under favorable conditions (Thomas et al. 2002) and the adults are internal feeders and cause serious quantitative and qualitative losses to the grains.

Control of weevil population worldwide has been provided principally by the use of synthetic chemical insecticides. However, these insecticides are expensive and mostly out of reach of most small holder farmers and also led to insect resurgence, resistance and negative effect on non-target organisms (Duke et al. 2003). Therefore, there is need to look for an alternative way of control measure that are readily available, less poisonous and less detrimental for pest control (Talukder and Howse 1995). Little research has been performed on the development of affordable organic pesticides which offer the same control levels as synthetics to weevils (Cosmas et al. 2012). Considerable efforts have been focused on plant derived materials, potentially useful as commercial insecticides. Different types of plant preparations such as powders, solvent extracts, essential oils and whole plants are being investigated for 
their insecticidal activity including their action as fumigants, repellents, antifeedants, anti-ovipositions and insect growths regulators (Isman 2000, Weaver and Subramanium 2000).

Plants are rich source of bioactive organic chemicals and offer an advantage over synthetic pesticides as these are less toxic, less prone to development of resistance and easily biodegradable. However, some works have been done to determine the efficacy of medicinal plant materials against stored grain insect pests. Investigations on such botanicals have been carried out to determine their insecticidal activity, toxicity, repellency, mortality, residual effects, larval growth and progeny production by Amin et al. (2000), Roy et al. (2005), Jbilou et al. (2006), Rahman et al. (2007), Kundu et al. (2007), Mondal et al. (2012), Ahalya and Mikunthan (2012), Gogoi (2012), Padin et al. (2013), Sagheer et al. (2014), Khan et al. (2014) and Karunakaran et al. (2016) on different stored grain insects.

The present study has been focused to investigate the comparative effectiveness of different concentrations of four extracts of two locally available medicinal plants Polygonum hydropiper L. and Abrus precatorius L. leaves for insecticidal activity against the rice weevil Sitophilus oryzae L.

\section{MATERIAL AND METHODS}

Experiments were conducted in the BCSIR laboratory, Chittagong and Entomological Research Laboratory of Department of Zoology, Chittagong University, for a period of six months from May to October 2017. Sitophilus oryzae was the test insect which was exposed to the various test doses of leaf extracts of Polygonum hydropiper and Abrus precatorius separately. The adult $S$. oryzae were collected from infested rice grain samples from the stored godowns of markets and were reared in plastic jars with fresh rice grains as culture media in the Entomological Research laboratory of the Department of Zoology, Chittagong University. The lids of the jars were perforated for proper aeration of the test insects and the jars were kept in a dark place in the laboratory. After some days, the test insects increased in number. The test insects were collected and used for the experiments when required. $P$. hydropiper (Bishkatali) and A. precatorius (Kuch) leaves were collected from Rangamati Hill Tracts. Fresh leaves were washed with tap water. All leaves were examined for signs of diseases, variegation and presence of external materials such as insects, their eggs and larvae. Only the fresh, disease less and uninfected leaves were taken for the experiments. The bigger leaves were cut into small pieces, air dried for some days and then dried in an oven at $40^{\circ} \mathrm{C}$ for five to six hours before grinding in an electronic grinding machine. The leaf dust thus obtained was passed through a 60 mesh sieve to obtain fine powder and was stored in glass jars under normal laboratory conditions.

Hundred grams of each powdered leaves were immersed into $500 \mathrm{ml}$ of the distilled water, ethanol, methanol and petroleum ether individually in $1 \mathrm{~L}$ spirator bottles and left to stand for 72 hours and shaken several times at intervals. After 72 hours the mixture was filtered through Whatman filter paper no. 1 and the residue was again immersed in the same way for another two times and filtered. All the filtrate was evaporated at $40-60^{\circ} \mathrm{C}$ using a rotary vacuum evaporator under reduced pressure to separate the solvent from the extract. After evaporation, the crude extract was isolated and stored in tightly corked bottles and kept in the refrigerator for experimental use.

\section{Stock Solution}

Stock solution was prepared with $1 \mathrm{~g}$ of each crude extract dissolving in $1000 \mathrm{ml}$ of the test solvents, i.e. distilled water, ethanol, methanol or petroleum ether. Experimental doses in terms of ppm were prepared according to APHA (2005) from the stock solution.

\section{Mortality Test}

To test the mortality rate or dose response of $S$. oryzae adults to Bishkatali, $P$. hydropiper and Kuch, A. precatorius leaf extracts, Surface/Residual Film Method (Busvine 1971) was applied. The 
experiments were conducted in Entomological Research Laboratory of the Department using medium sized petridishes $(12 \mathrm{~cm}$ diameter). One $\mathrm{ml}$ extract of each dose was poured in each of the upper and lower parts of each petridish pair with the help of pipette and spread evenly throughout the petridish. Then the petridishes were air dried. The doses used during the experiments were of five different concentrations (1000, 2000, 3000, 4000 and $5000 \mathrm{ppm}$ ) of different extracts of $P$. hydropiper and A. precatorius leaves. The test insects were shifted from culture media to the petridishes with the help of fine brush. The number of test insects released in each set was always ten. Three replications were maintained for each concentration. A control set was maintained for each experiment with the same number of insects and similar replications with the solvent only. The petridishes were then kept in an incubator without food at $25 \pm 5^{\theta} \mathrm{C}$ for 72 hours. Mortality of $S$. oryzae was recorded after 72 hours exposure to the toxicants.

\section{Statistical Analysis}

Dose-mortality relationships were calculated by Probit analysis. The regression equations were calculated from empirical probit and weighting probit, the values of which were taken from the tables of Finney (1971). Chi-square with P-values was calculated using observed and expected mortality data with the tables of the statistics at 0.01 and 0.05 level significance. The $\mathrm{LC}_{50}$ values with confidence limits were analyzed in a computer based Probit analysis program. Relative potency values were calculated from $\mathrm{LC}_{50}$ values of experimental doses taking the highest $\mathrm{LC}_{50}$ value as unit.

\section{RESULTS AND DISCUSSION}

The result of the percentage mortality of Sitophilus oryzae were recorded at 72 hours interval exposure to different concentrations of the two experimental plant leaf extracts. It was seen that a particular extract of different concentrations caused different parcentage of mortality in the experimental stored grain insect, S. oryzae.

\section{Effect of Polygonum hydropiper leaf extracts on mortality of Sitophilus oryzae}

With the water, ethanol, methanol and petroleum ether extracts of Polygonum hydropiper leaf, the lowest mortality $(3.33 \%, 3.33 \%, 3.33 \%$ and $6.67 \%$, respectively) was recorded with $1000 \mathrm{ppm}$ and the highest mortality $(23.33 \%, 46.67 \%, 53.33 \%$ and $66.67 \%$, respectively) with 5000 ppm doses at 72 hours exposure (Table 1). The percentage mortalities recorded were 3.33\%, 6.67\%, 10.00\%, 16.67\% and $23.33 \%$ for water extract; $3.33 \%, 23.33 \%, 33.33 \%, 40.00 \%$ and $46.67 \%$ for ethanol extract; $3.33 \%$, $10.00 \%, 26.67 \%, 33.33 \%$ and $53.33 \%$ for methanol extract; and 6.67\%, 13.33\%, 30.00\%, 40.00\% and $66.67 \%$ for petroleum ether extract corresponding their concentrations of the leaf extract solutions 1000 , 2000, 3000, 4000 and 5000 ppm, respectively. For water extract the regression equation was estimated to be $1.687 \mathrm{x}-2.023$, the chi-square value was $1.42(\mathrm{P}>0.01>0.05)$ and the $\mathrm{LC}_{50}$ value was 15091.436 ppm with confidence limits ranging from 7149.395 to $10683569.246 \mathrm{ppm}$; for ethanol extract the regression equation was estimated to be $0.140 \mathrm{x}+4.047$, the chi-square value was $44.23(\mathrm{P}<0.01<0.05)$ and the $\mathrm{LC}_{50}$ value was 5051.534 ppm with confidence limits ranging from 3889.852 to 8910.509 ppm; for methanol extract the regression equation was estimated to be $2.953 \mathrm{x}-5.919$, the chi-square value was $3.09(\mathrm{P}>0.01>0.05)$ and the $\mathrm{LC}_{50}$ value was $5111.063 \mathrm{ppm}$ with confidence limits ranging from 4118.602 to $7929.172 \mathrm{ppm}$; and for petroleum ether extract the regression equation was estimated to be $1.984 \mathrm{x}-2.141$, the chi-square value was $25.47(\mathrm{P}<0.01<0.05)$ and the $\mathrm{LC}_{50}$ value was 4305.348 with confidence limits ranging from 3557.034 to $5912.285 \mathrm{ppm}$ (Table 1). Analysis of probit mortality relationship of the four extracts of the experimental plant leaf is plotted in Fig. 1. 
Table 1. Toxicity parameters of Polygonum hydropiper leaf extracts on Sitophilus oryzae exposed for 72 hours.

\begin{tabular}{lcccc}
\hline \multicolumn{1}{c}{ Extracts } & Water & Ethanol & Methanol & Petroleum Ether \\
Toxicity Parameters & & & & \\
\hline Dose Range $(\mathrm{ppm})$ & $1000-5000$ & $1000-5000$ & $1000-5000$ & $1000-5000$ \\
Mortality Range $(\%)$ & $3.33-23.33$ & $3.33-46.67$ & $3.33-53.33$ & $6.67-66.67$ \\
Regression Equation & $1.687 \mathrm{x}-2.023$ & $0.140 \mathrm{x}+4.047$ & $2.953 \mathrm{x}-5.919$ & $1.984 \mathrm{x}-2.141$ \\
Chi-Square $\left(\chi^{2}\right)$ & 1.42 & 44.23 & 3.09 & 25.47 \\
Degree of Freedom $\left(\chi^{2}\right)$ & 4 & 4 & 4 & 4 \\
P-value $\left(\chi^{2}\right)$ & $\mathrm{P}>0.01>0.05$ & $\mathrm{P}<0.01<0.05$ & $\mathrm{P}>0.01>0.01$ & $\mathrm{P}<0.01<0.05$ \\
LC & 15091.436 & 5051.534 & 5111.063 & 4305.348 \\
Confidence limit (lower) & 7149.395 & 3889.852 & 4118.602 & 3557.034 \\
Confidence limit (upper) & 10683569.246 & 8910.509 & 7929.172 & 5912.285 \\
\hline
\end{tabular}

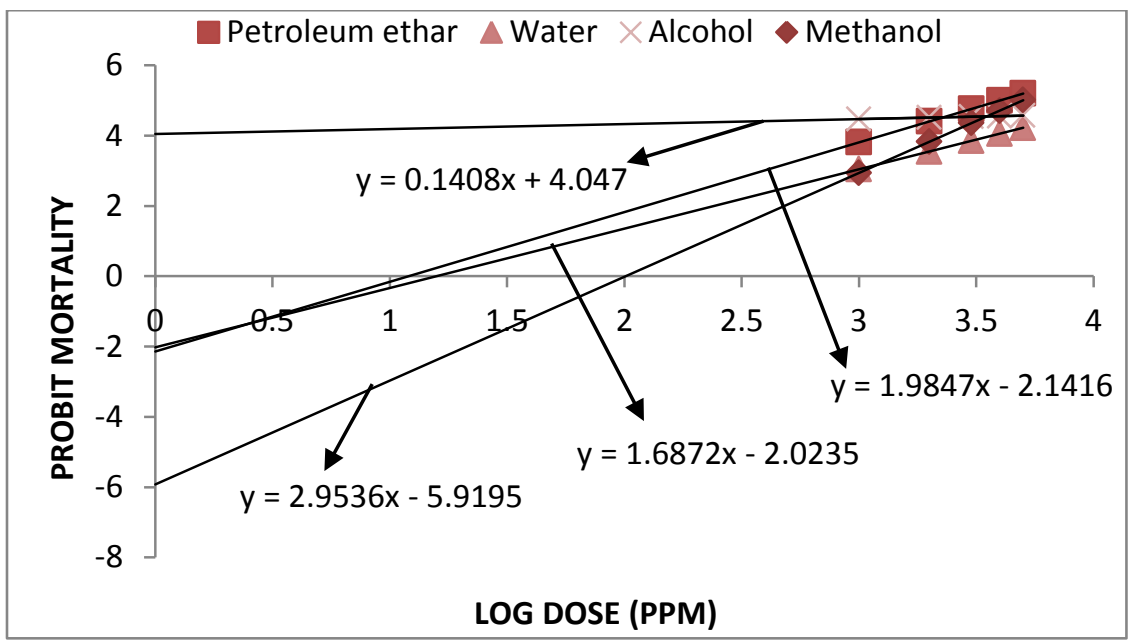

Fig. 1. Regression lines for determining the $\mathrm{LC}_{50}$ values of water, ethanol, methanol and petroleum ether extracts of Polygonum hydropiper leaves on Sitophilus oryzae after $72 \mathrm{hr}$ of exposure.

\section{Effect of Abrus precatorius leaf extracts on mortality of Sitophilus oryzae}

With the water, alcohol, methanol and petroleum ether extracts of Abrus precatorius leaf, the lowest mortality $(3.33 \%, 3.33 \%, 6.67 \%$, and $10.00 \%$, respectively) was recorded with $1000 \mathrm{ppm}$ and the highest mortality $(30.00 \%, 50.00 \%, 60.00 \%$ and $73.33 \%$, respectively) with 5000 ppm doses at 72 hours exposure (Table 2). The percentage mortalities recorded were $3.33 \%, 10.00 \%, 16.67 \%, 23.33 \%$ and $30.00 \%$ for water extract; $3.33 \%, 10.00 \%, 16.67 \%, 26.67 \%$ and $50.00 \%$ for ethanol extract; $6.67 \%$, $20.00 \%, 30.00 \%, 36.67 \%$ and $60.00 \%$ for methanol extract; and $10.00 \%, 30.00 \%, 40.00 \%, 60.00 \%$ and $73.337 \%$ for petroleum ether extract corresponding their concentrations of plant extract solutions 1000, 2000, 3000, 4000 and $5000 \mathrm{ppm}$, respectively. For water extract the regression equation was calculated to be $1.930 \mathrm{x}-2.661$, the chi-square value was $0.42(\mathrm{P}>0.01>0.05)$ and the $\mathrm{LC}_{50}$ value was $9687.292 \mathrm{ppm}$ with confidence limits ranging from 5846.594 to $88375.416 \mathrm{ppm}$; for alcohol extract the regression equation was calculated to be $2.741 \mathrm{x}-5.344$, the chi-square value was $5.54(\mathrm{P}>0.01>0.05)$ and the $\mathrm{LC}_{50}$ value was $6263.849 \mathrm{ppm}$ with confidence limits ranging from 4717.580 to $13069.702 \mathrm{ppm}$; for methanol extract the regression equation was calculated to be $2.312 \mathrm{x}-3.496$, the chi-square value was 3.86 $(\mathrm{P}>0.01>0.05)$, and the $\mathrm{LC}_{50}$ value was $4682.683 \mathrm{ppm}$ with confidence limits ranging from 3702.092 to $7410.714 \mathrm{ppm}$; and for petroleum ether extract the regression equation was calculated to be $2.640 \mathrm{x}-$ 4.273, the chi-square value was $3.06(\mathrm{P}>0.01>0.05)$ and the $\mathrm{LC}_{50}$ value was 3222.984 with confidence limits ranging from 2666.017 to $4040.298 \mathrm{ppm}$ (Table 2). Analysis of probit mortality relationship of the four extracts of the experimental plant leaf is plotted in Fig. 2. 
Table 2. Toxicity parameters of Abrus precatorius leaf extracts on Sitophilus oryzae exposed for 72 hours.

\begin{tabular}{lcccc}
\hline \multicolumn{1}{c}{ Extracts } & Water & Ethanol & Methanol & Petroleum Ether \\
Toxicity Parameters & & & & \\
\hline Dose Range $(\mathrm{ppm})$ & $1000-5000$ & $1000-5000$ & $1000-5000$ & $1000-5000$ \\
Mortality Range $(\%)$ & $3.33-30.00$ & $3.33-50.00$ & $6.67-60.00$ & $10.00-73.33$ \\
Regression Equation & $1.930 \mathrm{x}-2.661$ & $2.741 \mathrm{x}-5.344$ & $2.312 \mathrm{x}-3.496$ & $2.640 \mathrm{x}-4.273$ \\
Chi-Square $\left(\chi^{2}\right)$ & 0.42 & 5.54 & 3.86 & 3.06 \\
Degree of freedom $\left(\chi^{2}\right)$ & 4 & 4 & 4 & 4 \\
P-value $\left(\chi^{2}\right)$ & $\mathrm{P}>0.01>0.05$ & $\mathrm{P}>0.01>0.05$ & $\mathrm{P}>0.01>0.05$ & $\mathrm{P}>0.01>0.05$ \\
LC & 9687.292 & 6263.849 & 4682.683 & 3222.984 \\
Confidence limit (lower) & 5846.594 & 4717.580 & 3702.092 & 2666.017 \\
Confidence limit (upper) & 88375.416 & 13069.702 & 7410.714 & 4040.298 \\
\hline
\end{tabular}

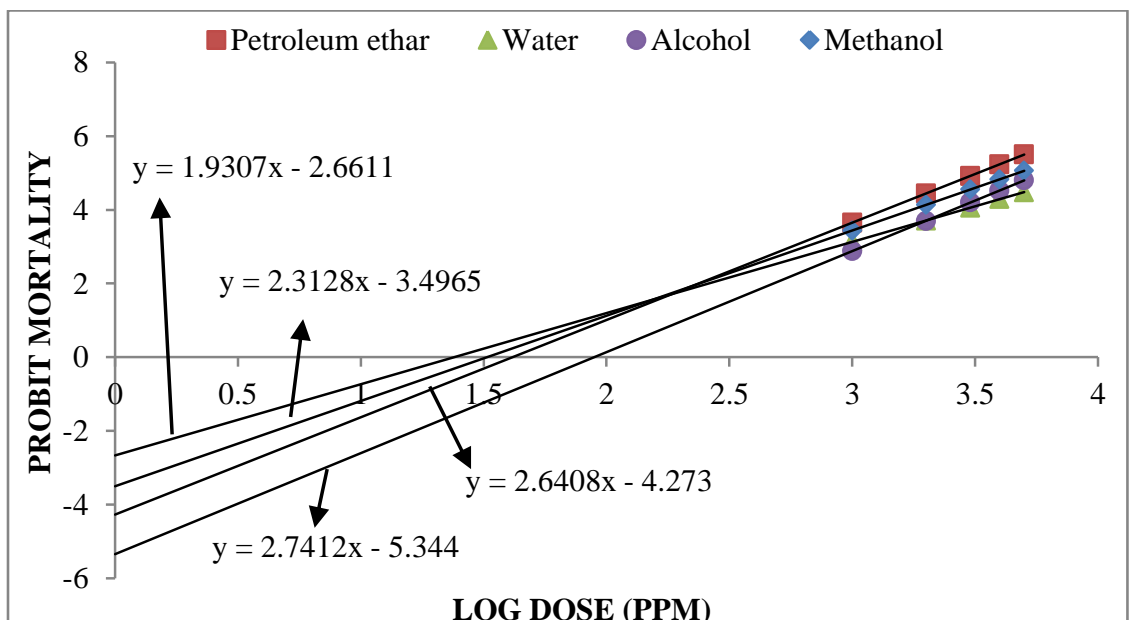

Fig. 2. Regression lines for determining the $\mathrm{LC}_{50}$ values of water, ethanol, methanol and petroleum ether extracts of Abrus precatorius leaves on Sitophilus oryzae after $72 \mathrm{hr}$ of exposure.

\section{Relative potency values of the experimental plant leaf extracts}

Relative potency values of an extract are reciprocal of an equitoxic extract. The relative potency values of different extracts of the two experimental plant leaves of Polygonum hydropiper and Abrus precatorius were calculated and are given in Table 3 . From the $\mathrm{LC}_{50}$ and relative potency values, it is seen that the most toxic extract was the petroleum ether extract of A. precatorius with $\mathrm{LC}_{50}$ of 3222.984 ppm and the least toxic was the water extract of $P$. hydropiper with $\mathrm{LC}_{50}$ of $15091.436 \mathrm{ppm}$.

Table 3. The $\mathrm{LC}_{50}(\mathrm{ppm})$ and Relative Potency values of different extracts of Polygonum hydropiper and Abrus precatorius leaves on Sitophilus oryzae.

\begin{tabular}{lcccc}
\hline Plant & Extract & LC $_{\mathbf{5 0}}(\mathbf{p p m})$ & Relative Potency & Rank \\
\hline \multirow{4}{*}{ Polygonum hydropiper } & Water & 15091.436 & 1.000 & 8 \\
& Ethanol & 5051.534 & 2.987 & 4 \\
& Methanol & 5111.063 & 2.953 & 5 \\
& Petroleum Ether & 4305.348 & 3.505 & 2 \\
\hline \multirow{3}{*}{ Abrus precatorius } & Water & 9687.292 & 1.558 & 7 \\
& Ethanol & 6263.849 & 2.409 & 6 \\
& Methanol & 4682.683 & 3.223 & 3 \\
& Petroleum Ether & 3222.984 & 4.682 & 1 \\
\hline
\end{tabular}

The order of toxicity of the extracts for $P$. hydropiper was Petroleum Ether $>$ Ethanol $>$ Methanol $>$ Water and that for A. precatorius was Petroleum Ether $>$ Methanol $>$ Ethanol $>$ Water. The sequence of 
toxicity of the four extracts of the two experimental plant leaves was: Petroleum Ether extract of $A$. precatorius $>$ Petroleum Ether extract of $P$. hydropiper $>$ Methanol extract of $A$. precatorius $>$ Ethanol extract of $P$. hydropiper $>$ Methanol extract of $P$. hydropiper $>$ Ethanol extract of $A$. precatorius $>$ Water extract of $A$. precatorius $>$ Water extract of $P$. hydropiper leaves. Of the two plants, extracts of $A$. precatorius leaves were more toxic than that of $P$. hydropiper leaves.

The result obtained from the bioassay revealed that all the extracts of the two experimental plant leaves showed varying levels of insecticidal property in terms of mortality against $S$. oryzae. Mortality of $S$. oryzae adults increased with the increase of concentrations. Mortality percentage showed parallel response to the different levels of concentrations with both the plant leaf extracts. For tested extracts the percentage of mortality depended on efficacy of concentrations. The mortality increased from $3.33 \%$ to $66.67 \%$ with increase of dose concentration of $1000 \mathrm{ppm}$ to $5000 \mathrm{ppm}$ at 72 hours exposure in case of $P$. hydropiper leaves. The mortality value increased from $3.33 \%$ to $73.33 \%$ mortality with increase of dose concentration from $1000 \mathrm{ppm}$ to $5000 \mathrm{ppm}$ at 72 hours exposure in case of A. precatorious leaves. Very low mortality had been observed for water extracts of both medicinal plant leaves which were $3.33 \%$ to $23.33 \%$ for $P$. hydropiper and $3.33 \%$ to $30.00 \%$ for A. precatorius leaves. Ethanol extracts of both plant leaves gave almost same mortality which was $3.33 \%$ to $46.67 \%$ for $P$. hydropiper and $3.33 \%$ to $50.00 \%$ for $A$. precatorius leaves. Methanol extracts of both the plant leaves showed greater mortality and it was $3.33 \%$ to $53.33 \%$ for $P$. hydropiper and $6.67 \%$ to $60.00 \%$ for $A$. precatorius leaves. In both cases, the highest mortality was observed for petroleum ether extracts and it was $6.67 \%$ to $60.00 \% \%$ for $P$. hydropiper and $10.00 \%$ to $73.33 \%$ for $A$. precatorius leaves. In every leaf extract, the highest mortality dose was $5000 \mathrm{ppm}$ but a longer interval or higher concentration would be required in some of the extracts to bring about $100 \%$ mortality. High mortality rate observed at higher dose agreed with the findings of Kundu et al. (2007) who examined the effects of chloroform and ethyl alcohol extracts of Polygonum hydropiper plant on Tribolium castaneum and Khan et al. (2014) who experimented the chloroform soluble fraction of ethanol extract of rhizome of Drynaria quercifolia against T. castaneum using Surface/Residual film method. Effects of different plant extracts having insecticidal property as in causing mortality due to direct toxicity is also supported by the findings of Talukder and Howse (1993), Roy et al. (2005), Rahman et al. (2007), Kundu et al. (2007), Ahalya and Mikunthan (2012) and Khan et al. (2014).

Chi-square tests done for all the extracts of the two experimental plant leaves showed insignificant values in most of the cases indicating that there was no difference between the observed mortality and expected mortality. From the $\mathrm{LC}_{50}$ values, it was observed that petroleum ether extract of $A$. precatorius leaves was the most toxic and water extract of $P$. hydropiper leaves was the least toxic. However, in all the leaf extracts the dose-response slopes were more or less identical, suggesting a common mechanism of death. Hence, $\mathrm{LC}_{50}$ is of great significance as biological constant in biological data analysis (Zbinden and Flury-Roversi 1981, Wallance-Hayes 1982).

The study was conducted to evaluate the mortality and relative potency value of extracts of $P$. hydropiper L. and A. precatorius leaves on rice weevil $S$. oryzae adults. The results obtained from the assay revealed that all extracts of $P$. hydropiper and $A$. precatorius leaves showed various levels of insecticidal property against $S$. oryzae and that the potential of the leaf extracts to cause mortality increased with concentration. The findings of this study agree with earlier reports that both the plant leaf extracts have insecticidal property and can control the experimental insect pest through causing direct mortality. The results demonstrated that leaf extracts of $P$. hydropiper and A. precatorius could be applied against rice weevil $S$. oryzae to protect stored grains.

Laboratory based toxicity experiments of plant products can give near optimal information about the efficacy of the plant toxins. It is evident from the present study that botanical extracts might have 
promising stored grain insect control efficacy. Findings of the study reveal in implementing environmentally friendly and ecologically sustainable rice weevil management practices. This information could also be useful in formulating rice weevil management tactics.

\section{REFERENCES}

Ahalya, S. and G. Mikunthan. 2012. The potential of using insecticidal properties of medicinal plant Gymnema sylvestre (R. br) against Sitophilus oryzae (L.). Am-Eurasian J. Agron. 5(1): 1-5.

Amin, M. R., H. F. El-Taj, T. M. T. Iqbal and M. A. Hossain. 2000. Use of akanda, bishkatali and neem leaves as botanical insecticides against lesser grain borer. Bangladesh J. Entomol. 10(1\&2): 1-13.

APHA. 2005. Standard Methods for the Examination of Water and Wastewater. 21st ed. American Public Health Association/American Water Works Association/Water Environment Federation, Washington DC, USA. 40 pp.

Busvine, J. R. 1971. A critical review of the techniques for testing insecticides. Com. Agri. Bureu (Cab), London, UK., pp. 263-288.

Cosmas, P., G. Christopher, K. Charles, M. Ronald and Z. Belta. 2012. Tagestes mimuta formulation effect Sitophilus zeamais (Weevils) control in stored maize grain. Int. J. Plant Res. 2(3): 65-68.

Duke, O. S., R. S. Baemson and M. A. Dayan. 2003. Research on natural products for pest management. Department of Agriculture, Agriculture Research Services, USA., pp. 708-717.

Finney, D. J. 1971. Probit Analysis. 3rd ed. Cambridge University Press, London, UK. 333 pp.

Gogoi, I. 2012. Bio-potential of chloroform extracts of Polygonum hydropiper and Pogostemon parviflorus fractions against some insect pests of tea. Two and a Bud. 59: 24-26.

Hague, H., M. A. Nakakita, H. I. Kenaga and N. Sota. 2000. Development inhibiting activity of some tropical plants against Sitophilus zeamais Motschulsky (Coleoptera: Curculionidae). J. Stored Prod. Res. 36: 281-287.

Isman, M. B. 2000. Plant essential oils for pest and disease management. Crop Protection. 19(10): 603608.

Jbilou, R., A. Ennabili and F. Sayah. 2006. Insecticidal activity of four medicinal plant extracts against Tribolium castaneum (Herbst) (Coleoptera: Tenebrionidae). African J. Biotech. 5(10): 936-940.

Karunakaran, S., K. Prasannath and W. Shanika. 2016. Insecticidal activity of plant powders against rice weevil, Sitophilus oryzae L (Coleoptera: Curculionidae). Int. J. Res. 3: 427-429.

Khan, A., M. H. Islam, M. E. Islam, M. A. A. Al-Bari, M. S. Parvin, M. A. Sayeed, M. N. Islam and M. E. Haque. 2014. Pesticidal and pest repellency activities of rhizomes of Drynaria quercifolia (J. Smith) against Tribolium castaneum (Herbst). Biol. Res. 47: 1-8.

Kundu B. R., R. Ara, M. M. Begum and Z. I. Sarker. 2007. Effect of Biskatali, Polygonum hydropiper L. plant extracts against the red flour beetle, Tribolium castaneum Herbst. Univ. J. Zool. Rajshahi Univ. 26: 93-97.

Mondal, O. A., J. Haque, E. Haque and A. R. Khan. 2012. Repellent activity of Abroma augusta extracts against Tribolium castaneum (Herbst) adults. J. bio-sci. 20: 49-55.

Padin, S. B., C. Fuse, M. I. Urrutia and G. M. Dal Bello. 2013. Toxicity and repellency of nine medicinal plants against Tribolium castaneum in stored wheat. Bull. Insectol. 66(1): 45-49. 
Rahman, S. S., M. M. Rahman, M. M. R. Khan, S. A. Begum, B. Roy and S. M. F. Shahed. 2007. Ethanolic extract of melgota (Macaranga postulata) for repellency, insecticidal activity against rice weevil (Sitophilus oryzae). African J. Biotech. 6(4): 379-383.

Rajendra, S. and V. Sriranjini. 2008. Plant products as fumigants for stored product insect control. $J$. Stored Prod. Res. 44: 126-135.

Roy, B., R. Amin, M. N. Uddin, A. T.M. S. Islam, M. J. Islam and B. C. Halder. 2005. Leaf extracts of Shiyalmutra (Blumea lacera Dc.) as botanical insecticides against lesser grain borer and rice weevil. J. Biol. Sci. 5(2): 201-204.

Sagheer, M., M. Hasan, M. N. Hassan, M. Farhan, F. Z. A. Khan and A. Rahman. 2014. Repellent effects of selected medicinal plant extracts against rust-red flour beetle, Tribolium castaneum (Herbst) (Coleoptera: Tenebrionidae). J. Entomol. Zool. Stud. 2(3): 107-110.

Talukdar F. A. and P. E. Howse. 1993. Deterrent and insecticidal effect of extract of pithraj, Aphanamixis polystacha (Meliaceae), against Tribolium castaneum. J. Chem. Ecol. 19: 2463-2471.

Talukdar F. A. and P. E. Howse. 1995. Evaluation of Aphanamaxix polystachya as a source of repellants, antifeedants, toxicants and protectants in storage against Tribolium castaneum (Herbst). J. Stored Prod. Res. 31(1): 55-61.

Thomas, K. J., M. Selvanayagam, N. Raja and S. Ignacimuthu. 2002. Plant products in controlling rice weevil Sitophilus oryzae. J. Scientific Indust. Res. 61: 269-274.

Wallance-Hayes, A. 1982. Principles and Methods of Toxicology. Raven press, New York, USA., pp. 151.

Weaver, D. K. and B. Subramanium. 2000. Botanicals. In: B. H. Subramaniam and D. W. Hagstrum (eds.). Alternative to Pesticides in Stored Product IPM. Kluwer Academic Publishers, MA., pp. 303-320.

Zbinden, G. and M. Flury-Roversi. 1981. Significance of the $\mathrm{LD}_{50}$ test for the toxicological evaluation of chemical substances. Archv. Toxicol. 47: 79-99. 